\title{
Management practices on organic and conventional dairy herds in Minnesota
}

\author{
U. S. Sorge, ${ }^{* 1}$ R. Moon, $†$ L. J. Wolff, ${ }^{*}$ L. Michels, ${ }^{*}$ S. Schroth, ${ }^{*}$ D. F. Kelton, $\ddagger$ and B. Heins \\ ${ }^{*}$ Department of Veterinary Population Medicine, and \\ †Department of Entomology, University of Minnesota, St. Paul 55108 \\ $\ddagger$ Department of Population Medicine, University of Guelph, Guelph, ON, N1G 2W1, Canada \\ $\S$ Department of Animal Science, University of Minnesota, St. Paul 55108
}

\begin{abstract}
The objective of this study was to describe and compare husbandry practices on organic and conventional dairy farms of similar sizes in Minnesota. Organic (ORG, $\mathrm{n}=35$ ), same-sized conventional ( $\mathrm{SC}, \mathrm{n}=15$, $<200$ cows) and medium-sized conventional ( $\mathrm{MC}, \mathrm{n}=$ $13, \geq 200$ cows) dairy herds were visited in 2012 , and farmers were interviewed once about their farm, herd demographics, and herd management practices concerning nutrition, housing, and reproductive programs. Organic farms had been established as long as conventional farms, and ORG producers had most commonly selected ORG farming because of a negative perception of pesticides for human health. The distribution of cattle breeds and ages differed across farm types. Organic farms had more crossbred cows and a greater number of older cows than conventional farms, who had mainly Holstein cattle. Organic farms did not dock tails, were more likely to use breeding bulls, and were less likely to conduct pregnancy diagnoses in cattle. All conventional farmers fed corn, corn silage, and hay, but no forage or feed supplement was fed by all ORG farms with the exception of pasture. Kelp was supplemented on most ORG farms but on none of the conventional farms. In summary, although there were differences across farm types regarding the use of pasture, feeds, and feed additives, breed and age distribution, reproductive management, and the use of tail docking, observations in other management areas showed large overlap across herd types.
\end{abstract}

Key words: organic, dairy, cattle, husbandry

\section{INTRODUCTION}

Over the past decade, the demand for organically produced food has increased tremendously in the United States. In particular, the dairy sector, which represents

Received July 31, 2015.

Accepted December 12, 2015.

${ }^{1}$ Corresponding author: sorge@umn.edu the second largest segment of the organic (ORG) agricultural industry, has grown exponentially (ERS, 2014). In the United States, the National Organic Program (NOP) of the USDA's Agricultural Marketing Service defines the rules under which farmers produce organic products or livestock (AMS, 2015). All certified organic livestock must be fed organic feed, and all ruminants over 6 mo of age are required to receive at least $30 \%$ of their annual DMI from pasture for at least $120 \mathrm{~d}$ during the grazing season. This definition of feed intake and pasture access is known as "the pasture rule."

Use of hormones (with the exception of oxytocin) and antibiotics is prohibited in ORG livestock production. Any animal treated with antibiotics or any other substance not specified in the NOP rules loses its organic status. A treated animal must immediately leave the organic farm, and none of its milk or meat products can ever be sold as organic. However, the NOP rules also explicitly state that effective treatment (e.g., antibiotics) must not be withheld from a sick animal to retain its organic status (AMS, 2015). Therefore, preventative management practices have been identified as the cornerstone of ORG farming.

Little is known about general management practices or health parameters on ORG farms in the United States (McBride and Greene, 2007; Rotz et al., 2007; Richert et al., 2013; Stiglbauer et al., 2013). Some of the existing studies were conducted before the pasture rule was introduced in 2010 (McBride and Greene, 2007; Rotz et al., 2007), and many other studies of organic dairy production are from Europe (Cabaret, 2003; Vaarst et al., 2005; Fall et al., 2008; Haskell et al., 2009; Ivemeyer et al., 2009; Sundberg et al., 2009; Garmo et al., 2010), which operates under different organic rules than those set in the United States. For instance, current European law does not mandate DMI from pasture for ruminants, and European (European Union, 2007) as well as Canadian standards (COS, 2011) allow the use of antibiotics or parasiticides with extended withhold times for the treatment of sick animals. As such, a comparison of ORG dairy herds in Europe and the United States should be done cautiously. 
In response to the scarcity of information comparing these 2 production systems, the objective of this study was to describe and compare husbandry practices on organic and conventional farms in Minnesota.

\section{MATERIALS AND METHODS}

The study was conducted between June and November 2012 in Minnesota. All certified ORG dairy herds in Minnesota $(\mathrm{n}=114)$ and a convenience sample of conventional herds that were enrolled in the Minnesota DHIA and that raised their heifers on site were invited to participate. Conventional herds were selected to be of similar geographic region as the ORG herds, the approximate same herd size and ideally allowed pastureaccess to their animals. Each herd was visited once, and a questionnaire was administered directly to the producer by one of the researchers (L. J. W., S. S., L. M., and U. S. S.). This questionnaire was largely based on 3 National Animal Health Monitoring Service (NAHMS) questionnaires (2007 General Dairy Management Report, 2007 VS Initial, and VS Second Visit surveys). The survey asked about herd descriptors involving age and breed distribution, other species on farm, and production parameters, and it asked about management practices concerning housing, feeding, and reproductive management, as used on the farms over the previous 12 mo. In addition, the environment and waterers were assessed for hygiene (scale 1-3). Environmental hygiene scores were as follows: 1 = vast majority of bedding clean and dry, with minimal visible manure; 2 = majority of bedding clean, but some fecal contamination was visible; $3=$ majority of bedding was covered in manure. For waterers, the hygiene scores were as follows: $1=$ minimal to no water contamination, bottom of trough clean, $2=$ clean to minimally contaminated water, bottom had debris; $3=$ water is dirty and bottom of trough not visible. The complete survey can be found here: https://web-cvm.s3.amazonaws.com/dairy/ assets/File/Organic\%20survey.pdf. The study and survey protocol were approved by the University of Minnesota's Institutional Animal Care and Use Committee.

The conventional herds varied greatly in size. To allow comparison with the ORG herds, therefore, they were split into small conventional herds (SC, $<200$ mature cows total, i.e., milking and dry cows) and medium-sized conventional herds ( $\mathbf{M C}, \geq 200$ mature cows total). The other herds were categorized by size so that SC and ORG herds were of comparable herd size and larger herds were included in the medium-size category similar to the NAHMS surveys (USDA-NAHMS, 2007). Three conventional herds with more than 500 cows $(562,574$, and 811 mature cows in total, respectively) were also included in the medium herd size.

Survey data were described with summary statistics including medians and interquartile ranges $(\mathbf{I Q R}$, reported as 25 th to 75 th percentiles) for continuous data, and with frequency statistics for categorical data. Nonparametric tests (Fisher's exact, Kruskal-Wallis, and Mann-Whitney U-tests) were used to compare observations between or among herd types (ORG, SC, MC) and Spearman correlations were used to assess relationships between continuous or assumed continuous (e.g., percent) variables. All data were analyzed using SAS 9.4 (SAS Institute Inc., Cary, NC), with significance level set at $\alpha=0.05$.

\section{RESULTS}

In total, 35 ORG farms, $15 \mathrm{SC}$ farms, and $13 \mathrm{MC}$ farms participated in the survey. Most ORG farms (69\%) were DHIA members, whereas all conventional farms were DHIA members. Table 1 summarizes descriptors of the 3 farm types. The median year that a farm was established did not differ between types $(P$ $=0.70)$, and the median time that participants had been farming did not differ either $(P=0.95)$. As expected, more people worked on MC farms compared with smaller SC and ORG farms. Numbers of cattle (both mature and youngstock) per worker were 42.3 cows/worker on ORG farms, 43.5 cows/worker on SC farms, and 66.4 cows/worker on MC farms $(P<0.01)$.

Organic farms had been organically certified for an average of 8 yr (certification year range: 1990-2012), and most $(70 \%)$ ORG producers stated that they had been farming with organic practices before being officially certified. Producers could state multiple reasons for the pursuit of organic certification and identified the general dislike of chemicals used in agriculture ( $\mathrm{n}=21$ ), which included the effect of pesticides and herbicides on their personal or human health $(\mathrm{n}=9)$, economic reasons $(n=12)$, a perceived benefit for the environment and soil $(\mathrm{n}=7)$, benefits for the cows ( $\mathrm{n}$ $=5)$, a preferred lifestyle choice, ethical reasons $(\mathrm{n}=$ $5)$, and peer pressure $(\mathrm{n}=1)$.

Herd sizes on the surveyed farms of all types increased over the previous $10 \mathrm{yr}$ (Table 1). Approximately half of the producers (ORG: $48.6 \%$, SC: $40.0 \%$, MC: $38.5 \%$; $P=0.83$ ) had indicated that they had purchased cattle in the previous 12 mo. In general, the type of cattle purchased did not differ between herd types, but conventional herds tended to be more likely to bring mature cows on site compared with ORG herds $(P=$ $0.06)$. 
Table 1. Descriptors of study herds in Minnesota by herd type ${ }^{1}$

\begin{tabular}{|c|c|c|c|c|}
\hline Parameter & \multicolumn{3}{|c|}{ Herd type $^{2}$} & $P$-value \\
\hline No. of herds in survey $(\mathrm{N})$ & 35 & 15 & 13 & \\
\hline Change in milking cows, 1 yr (\%) & $0(-6$ to 9$)$ & $5.7(-11$ to 30$)$ & $4.3(0$ to 8$)$ & 0.18 \\
\hline Change in milking cows, 10 yr (\%) & $5.7(-11$ to 30$)$ & $11.8(0$ to 29$)$ & $23.5(9$ to 41$)$ & 0.18 \\
\hline Milk per cow/day $(\mathrm{kg})$ & $15.5(15.9 \text { to } 20.5)^{\mathrm{b}}$ & $30.9(27.3-36.4)^{\mathrm{a}}$ & $36.4(33.6 \text { to } 37.7)^{\mathrm{a}}$ & $<0.01$ \\
\hline Primary milking facility ( $\%$ of herds) & & & & $<0.01$ \\
\hline Parlor & 62.9 & 20.0 & 100 & \\
\hline Tiestall & 37.1 & 80.0 & 0 & \\
\hline \multicolumn{5}{|l|}{ Composition of mature herd } \\
\hline First lactation milking (\%) & $29.2(25 \text { to } 33.8)^{\mathrm{b}}$ & $42.5(37.2 \text { to } 80.0)^{\mathrm{a}}$ & $40.6(34.4 \text { to } 43.5)^{\mathrm{a}}$ & $<0.01$ \\
\hline Second lactation milking (\%) & $25.5(23.1$ to 29.0$)$ & $29.0(24.2$ to 31.3$)$ & $28.0(26.17$ to 29.5$)$ & 0.30 \\
\hline$\geq$ Third lactation milking (\%) & $43.9(37.5 \text { to } 54.1)^{\mathrm{a}}$ & $27.5(26.0 \text { to } 28.1)^{\mathrm{b}}$ & $32.3(29.5 \text { to } 33.3)^{\mathrm{b}}$ & $<0.01$ \\
\hline Lactating herd & $100^{\mathrm{a}}$ & $46.7^{\mathrm{b}}$ & $7.7^{\mathrm{c}}$ & 0.01 \\
\hline Dry cows & $97.1^{\mathrm{a}}$ & $73.3^{\mathrm{b}}$ & $30.8^{\mathrm{c}}$ & 0.01 \\
\hline Weaned heifers & $100^{\mathrm{a}}$ & $80.0^{\mathrm{b}}$ & $38.5^{\mathrm{c}}$ & 0.01 \\
\hline
\end{tabular}

${ }^{\mathrm{a}-\mathrm{C}}$ Different superscripts in the same row indicate statistically different values.

${ }^{1}$ Values are medians (25th to 75th percentile) unless stated otherwise. Survey conducted June to October 2012.

${ }^{2}$ Certified organic (ORG) and small conventional (SC) herds had $<200$ mature cows (i.e., dry and milking); medium conventional (MC) herds had $\geq 200$ mature cows.

Herd composition differed among herd types. Although the average age of the oldest cow was similar across all herd types, conventional herds reported a larger proportion of cows in first lactation than ORG herds $(P<0.01)$ and were predominantly Holstein cows. In contrast, ORG herds reported more cows in third or later lactation, and ORG herds contained more crossbred cows than did conventional herds $(P<0.01)$. Cows were individually identified with ear tags on all but 3 ORG farms. These 3 ORG farms reportedly used tattoos $(\mathrm{n}=1)$, collars and tattoos $(\mathrm{n}=1)$, or nothing $(\mathrm{n}=1)$ to visually mark individual cows on their premises. Only MC farms used electronic tags.

All participating farms dehorned their heifer calves routinely, and an average of $30 \%$ of cows on SC farms (IQR: $0-98 \%$ ) and 99\% of cows on MC farms (IQR: 50-100\%) had docked tails. No ORG herds docked their cows' tails (median and IQR: 0\%, $P<0.01$ ).

Besides dairy cattle, most herds also had other species on site. Cats were present on all but 2 ORG farms and dogs were commonly present ( $>84.6 \%$ farms). Chickens were present on $57.1 \%$ ORG, $13.3 \%$ SC, and $15.4 \% \mathrm{MC}$ farms $(P<0.01)$. Dairy animals for slaughter $(P=$ $0.02)$ and pigs $(P=0.09)$ were more common on ORG (80 and $34.4 \%$ ) than on conventional farms (SC: 60 and 13.3\%; MC: 15.4 and $7.7 \%$, respectively).

\section{Housing}

Tables 2 and 3 show the most common primary housing types for different age groups on farms during the summer and winter, respectively. Individual housing was the most commonly used housing type for preweaned heifers on all herds $(P=0.10)$. Although ORG herds most commonly housed weaned heifers on pasture, SC and MC herds were less specific and predominantly used a mixture of housing types $(P=0.02)$, which included open sheds, pasture, and other types of housing on the same farm (Table 2).

During the winter, housing shifted indoors regardless of herd type. However, many herds continued to keep animals outside. This included 2 ORG herds that reportedly continued to keep their lactating cows outside "on pasture" during the winter. In contrast, none of the conventional herds used outdoor housing for the lactating herd during the winter months.

The predominant bedding type for preweaned calves was straw ( $>61 \%$ of herds). Organic herds (weaned: $79.9 \%$, lactating: $59.8 \%$, dry: $71.5 \%$ ) and SC herds $(>80.0 \%)$ continued to use straw and combinations with straw as the most common bedding throughout all age groups. In contrast, MC herds were more likely to use corn cobs and stalks (38.5\%) alone or in combination 
Table 2. Primary housing of different age groups on different farm types during the summer months

\begin{tabular}{|c|c|c|c|c|}
\hline \multirow[b]{2}{*}{ Item } & \multicolumn{3}{|c|}{ Herd type ${ }^{1}$} & \multirow[b]{2}{*}{$P$-value } \\
\hline & ORG & $\mathrm{SC}$ & $\mathrm{MC}$ & \\
\hline Preweaned heifers & & & & 0.10 \\
\hline Individual pen/hutch outside & 22.9 & 13.3 & 30.7 & \\
\hline Individual pen/hutch inside & 20.0 & 73.3 & 46.2 & \\
\hline Mixed housing types $^{2}$ & 14.3 & 0 & 15.4 & \\
\hline Group housing outside (open front shed) & 42.8 & 0 & 0 & \\
\hline Weaned/breeding age & & & & 0.02 \\
\hline Pasture & 51.4 & 13.3 & 7.7 & \\
\hline Open front shed & 5.7 & 46.7 & 38.5 & \\
\hline Mixed housing types ${ }^{2}$ & 28.6 & 6.6 & 23.0 & \\
\hline Multiple animals outside/drylot & 5.7 & 6.7 & 15.4 & \\
\hline Multiple animals inside & 8.6 & 20.0 & 15.4 & \\
\hline Lactating cows & & & & $<0.01$ \\
\hline Pasture & 65.7 & 0 & 0 & \\
\hline Indoor with pasture access & 34.3 & 46.7 & 15.4 & \\
\hline Freestall & 0 & 13.3 & 76.9 & \\
\hline Tiestall & 0 & 33.3 & 0 & \\
\hline Open front shed, mixed ${ }^{2}$ & 0 & 16.6 & 7.7 & \\
\hline Dry cows & & & & $<0.01$ \\
\hline Pasture & 85.3 & 26.7 & 0 & \\
\hline Indoor with pasture/drylot access & 14.7 & 33.3 & 30.8 & \\
\hline Freestall & 0 & 13.3 & 23.1 & \\
\hline Group housing/drylot outside & 0 & 6.7 & 23.1 & \\
\hline Group housing inside & 0 & 20.0 & 7.7 & \\
\hline Open front shed & 0 & 0 & 15.3 & \\
\hline
\end{tabular}

${ }^{1}$ Certified organic (ORG) and small conventional (SC) herds had $<200$ mature cows (i.e., dry and milking); medium conventional (MC) herds had $\geq 200$ mature cows.

${ }^{2}$ Mixed housing types encompassed more than one category of housing; for example, a farm could house some heifers in a 3-sided shed and others primarily on pasture.

with other materials for weaned heifers and bedded lactating cows either with sand (30.8\%), sawdust (30.8\%) or composted/dried manure (15.4\%). The latter was not used at all by the smaller herds.

Regardless of herd type, bedding was changed approximately 5 to 6 times per year for preweaned heifers $(P>0.35)$, which coincided with the use of the pen by newborn animals. The bedding of weaned heifers (median: 2, IQR: $2-7, P<0.04$ ) and dry cows (median: 1, IQR: $1-4, P<0.01$ ) was changed less commonly on ORG herds than on SC herds (median: 4, IQR: 4-26 and median: 16 , IQR: 3-52, respectively) or MC herds (median: 4, IQR: 4-12 and median: 9, IQR: $4-17$, respectively). Bedding of lactating cows was more commonly changed on SC herds (365 times/yr; IQR: 183-365 times/yr) than on ORG (24 times/yr, IQR: 1-365 times/yr) or MC herds (9 times/yr, IQR: $4-17$ times/yr, $P<0.01$ ). The type of housing influenced the frequency of bedding changes. Herds using either freestall housing or pasture for the lactating cows during the summer months changed the bedding less often than herds with tiestall housing or a mix of various housing types $(P<0.01)$.

On the day of the visit, the environmental and water hygiene for the assessed areas (preweaned and weaned heifers, lactating and dry cows, and calving area) were generally comparable between herd types $(P \geq 0.06)$. In some instances, smaller herds (ORG and SC) tended to be more likely to have slightly higher scores, indicating contamination, than MC herds.

\section{Heat Abatement and Shelter}

Heat abatement methods used on farms included misters or sprinklers, which were more common on MC herds $(84.6 \%)$ than on the smaller SC $(46.7 \%)$ or ORG herds $(32.4 \%, P<0.01)$ and fans that were also more commonly used in the barns of conventional herds (SC: 93.3\%, MC: $92.3 \%)$ than in ORG herds $(58.8 \%, P=$ 0.01 ). Tunnel ventilation was predominantly used on SC herds $(60.0 \%)$ and less often on ORG (11.8\%) or MC (13.7\%) herds. Most herds with pasture access, with the exception of SC herds $(30.0 \%)$, had improved pasture lanes (ORG: 77.1, MC: $66.7 \%, P=0.02$ ) and provided some type of shade (outside of building) for their animals (ORG: $67.7 \%$, SC: $50.0 \%$, MC, $37.5 \%, P$ $=0.25)$. While on pasture, cows had to walk, on average, $183 \mathrm{~m}$ (IQR: $91-402 \mathrm{~m})$ to access water $(P>0.44)$.

Regardless of the herd type, shelter was not always provided for animals on pasture. For lactating cows, 
Table 3. Primary housing of different age groups on different farm types during the winter months

\begin{tabular}{|c|c|c|c|c|}
\hline \multirow[b]{2}{*}{ Item } & \multicolumn{3}{|c|}{ Herd type $^{1}$} & \multirow[b]{2}{*}{$P$-value ${ }^{2}$} \\
\hline & ORG & $\mathrm{SC}$ & $\mathrm{MC}$ & \\
\hline Preweaned heifers ${ }^{3}$ & & & & 0.31 \\
\hline Individual pen/hutch outside & 20.6 & 13.3 & 38.5 & \\
\hline Individual pen/hutch inside & 26.5 & 73.3 & 46.1 & \\
\hline Group housing inside & 23.5 & 13.3 & 7.7 & \\
\hline Mixed housing types ${ }^{4}$ & 17.7 & 0 & 7.7 & \\
\hline Group housing (open-faced shed/hutch) outside & 5.8 & 0 & 0 & \\
\hline Weaned/breeding age ${ }^{5}$ & & & & $<0.01$ \\
\hline Open-sided shed & 34.3 & 73.3 & 30.8 & \\
\hline Mixed housing types & 11.4 & 0 & 23.0 & \\
\hline Group housing inside & 34.3 & 20.0 & 30.8 & \\
\hline Group housing/drylot outside & 14.3 & 0 & 15.4 & \\
\hline Freestall & 2.9 & 0 & 0 & \\
\hline Open-faced shed & 0 & 6.7 & 0 & \\
\hline Lactating cows & & & & $<0.01$ \\
\hline Mixed housing types & 25.7 & 40.0 & 15.4 & \\
\hline Freestall & 34.3 & 20.0 & 84.6 & \\
\hline Tiestall & 14.3 & 40.0 & 0 & \\
\hline Open-faced shed & 20.0 & 0 & 0 & \\
\hline Pasture & 5.7 & 0 & 0 & \\
\hline Dry cows & & & & $<0.01$ \\
\hline Mixed housing types & 17.1 & 0 & 30.8 & \\
\hline Open-sided shed & 14.3 & 39.9 & 7.7 & \\
\hline Freestall & 2.9 & 26.7 & 30.8 & \\
\hline Group housing/drylot outside & 25.7 & 6.7 & 23.0 & \\
\hline Group housing inside & 22.9 & 26.7 & 7.7 & \\
\hline Pasture/outwintering & 17.1 & 0 & 0 & \\
\hline
\end{tabular}

${ }^{1}$ Certified organic (ORG) and small conventional (SC) herds had $<200$ mature cows (i.e., dry and milking); medium conventional (MC) herds had $\geq 200$ mature cows.

${ }^{2}$ Fisher's exact statistics.

${ }^{3}$ Two organic herds $(5.9 \%)$ did not have preweaned calves during the winter.

${ }^{4}$ Mixed housing types encompasses more than one category of housing was named as primary housing.

${ }^{5}$ One organic herd $(2.9 \%)$ did not have weaned heifers on site.

trees were the most common form of shelter. In contrast, dry cows and heifers were most commonly offered a shed when shelter was offered on pasture.

\section{Milking Practices}

On most ORG and all MC herds, cows were milked in a milking parlor, whereas most SC herds were milked in a tiestall or stanchion barn (Table 1). The majority of participating farms milked twice a day. The exceptions were 1 ORG herd that milked once per day and 3 conventional herds ( $1 \mathrm{SC} ; 2 \mathrm{MC}$ ) that milked 3 times per day. Parlors were cleaned in most cases as often as milking occurred - only 1 ORG and $1 \mathrm{MC}$ herd reported cleaning units one additional time. In contrast to the general uniformity of reported milking frequency, 37 different milking routines were reported. The extremes were one ORG and one MC herd, which reported 1 and 9 additional steps besides attachment of the milking unit in their milking routine, respectively. The most common milking routine $(\mathrm{n}=10)$ was to predip, wipe, attach milking units, and postdip the teats. Organic herds reported, on average, fewer steps in their milking routine than conventional herds $(P=0.01)$. Although ORG $(68.6 \%)$ and SC herds $(66.7 \%)$ tended to use less frequent prestripping than MC herds $(100 \%, P<0.06)$, there was only a numerical difference between herds regarding the visual assessment of the foremilking for clinical mastitis (ORG: $45.7 \%$, SC: $60.0 \%$, MC: $69.0 \%$, $P=0.34$ ). The use of disposable gloves during milking differed among herd types. About one-third of ORG (31.4\%) and SC herds (26.7\%) did not use gloves during milking, whereas all MC herds always used disposable gloves during milking $(P<0.01)$. In addition, 57.1 and $11.4 \%$ of ORG and 33.3 and $40.0 \%$ of SC herds always or only sometimes used disposable gloves during milking, respectively.

Cows in smaller sized herds were predominantly milked by the herd owner (ORG: $57.1 \%$, SC: $73.3 \%$ ), whereas the larger herds used hired workers to milk cows $(76.9 \%, P<0.01)$. The ratio of cows to milking personnel was higher in MC herds (99 cows/milker) than in ORG or SC herds (41 and 52 cows/milker, respectively, $P<0.01)$, and MC (46.2\%) and ORG herds 
$(22.9 \%)$ tended to be more likely to have written milking procedures compared with $\mathrm{SC}$ herds $(6.7 \%, P=$ $0.06)$. The herds that did offer milker training usually provided this only for new employees (ORG: $95 \%, \mathrm{SC}$ : 91.6\%, MC: $58.3 \%$ ) and less commonly 1 to 2 times per year for all milkers (ORG: $31.0 \%$, SC: $6.7 \%$, MC: $41.7 \%$ ). The most common method to explain the milking routine was "on-the-job-training" (ORG: 91.7\%, SC: $92.3 \%$, MC: $84.6 \%)$.

\section{Reproduction and Calving Assistance}

Most herds (ORG: 54.3\%; SC: 93.3\%, MC: 92.3\%) calved animals year round. Although AI following estrus for the breeding of cows was the most common breeding strategy on farms, ORG herds were much more likely than conventional herd types to report the use of a breeding bull (Table 4). Furthermore, the reported age at first calving was higher in ORG herds than on most conventional operations $(P<0.01$, Table 4$)$ and only 18 of the 34 participating ORG herds $(52.9 \%)$ conducted any form of pregnancy diagnostics after breeding. Most commonly, the majority of cows on farm would calve in either a group pen (SC: $46.7 \%, \mathrm{MC}: 69.3 \%$ ) or on pasture (ORG: $47.1 \%, P<0.01)$. Although not all herds scored or recorded dystocia (Table 4), lower dystocia and stillbirth rates were recorded on ORG farms compared with the other herd types $(P<0.05$; Table $4)$. The stillbirth rate was positively correlated with the percentage of heifers experiencing dystocia $(r=0.28$, $P=0.04$ ), but not with the proportion of older cows ( $\geq$ third lactation, $P=0.98$ ) nor the percentage of cows experiencing dystocia $(P=0.41)$.

\section{Nutrition}

All ORG and many of the conventional herds allowed their lactating herd access to pasture (SC: $53.8 \%$, MC: $7.7 \%, P<0.01$; Table 1 ). However, only the ORG herds and $3 \mathrm{SC}$ herds used rotational grazing. The most common descriptions of the pasture management for the lactating herd of ORG farms were mob or strip grazing ( $\mathrm{n}=8)$, a combination between rotational and mob or strip grazing $(\mathrm{n}=5)$, or rotational grazing $(\mathrm{n}=$ 23). The conventional herds that provided pasture access to cows used continuous grazing $(\mathrm{n}=17)$. Two conventional farmers classified the pastures as "exercise lot." Accordingly, only one SC producer and none of the MC producers assessed pasture for its yield and nutritional value compared with ORG herds (82.9 and $76.5 \%$, respectively). Interestingly, one ORG producer reportedly did not assess any of these 2 pasture parameters. The other ORG producers assessed the pasture yield through different methods, which included the visual assessment of the pasture $(\mathrm{n}=18)$ or cows $(\mathrm{n}=$ 1 , e.g., body condition or manure score), deduction of the cows' indoor feed consumption during the grazing period compared with the winter season $(\mathrm{n}=8)$, or the collection of samples and calculations $(n=2)$. The nutritional value of pastures was assessed through forage clippings $(\mathrm{n}=11)$, the visual assessment of cows (n $=5)$ or pasture $(\mathrm{n}=9)$ and soil samples $(\mathrm{n}=1)$.

The composition of the ration fed to the lactating herd varied by farm. All conventional herds fed corn, corn silage, and alfalfa hay or haylage. In contrast, not a single forage or feed supplement, besides pasture, was fed by all ORG producers. However, ORG producers

Table 4. Producer-attributed reproduction parameters and related management practices on dairy farms ${ }^{1}$

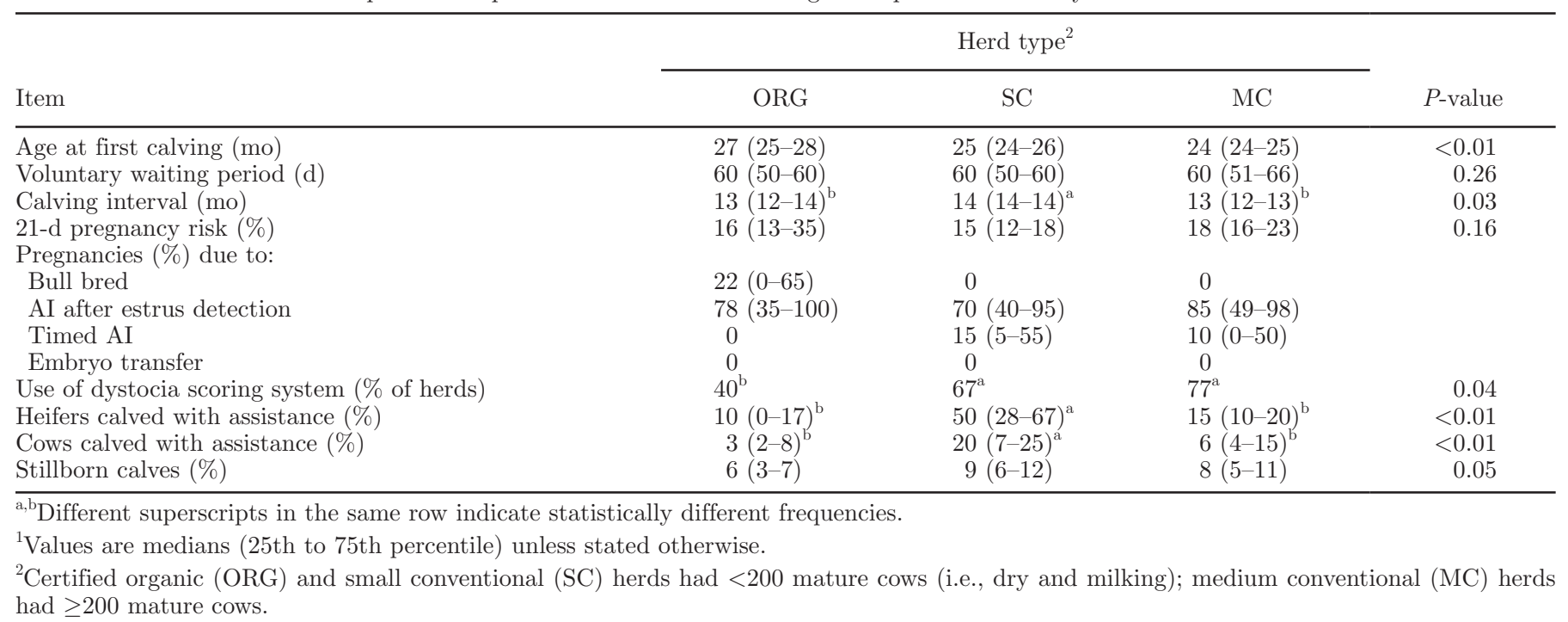


Table 5. Forages and feed supplements fed indoors to lactating cows over the past 12 mo in Minnesota

\begin{tabular}{lcccc}
\hline & \multicolumn{3}{c}{ Herd type $^{1}$} \\
Forage and feed \\
\cline { 2 - 4 } supplements & ORG & SC & MC & $P$-value \\
\hline Alfalfa & 97.1 & 100 & 100 & $>0.99$ \\
Kelp & $82.9^{\mathrm{a}}$ & $0^{\mathrm{b}}$ & $0^{\mathrm{b}}$ & $<0.01$ \\
Corn & 82.9 & 100 & 100 & 0.10 \\
Corn silage & $65.7^{\mathrm{b}}$ & $100^{\mathrm{a}}$ & $100^{\mathrm{a}}$ & $<0.01$ \\
Barley & $54.3^{\mathrm{a}}$ & $13.3^{\mathrm{b}}$ & $15.4^{\mathrm{b}}$ & $<0.01$ \\
Soybeans & $40.0^{\mathrm{b}}$ & $86.7^{\mathrm{a}}$ & $100^{\mathrm{a}}$ & $<0.01$ \\
Oats & $40.0^{\mathrm{a}}$ & $13.3^{\mathrm{b}}$ & $0^{\mathrm{b}}$ & $<0.01$ \\
Clover forage & $31.4^{\mathrm{a}}$ & $0^{\mathrm{b}}$ & $0^{\mathrm{b}}$ & $<0.01$ \\
Wheat & 20.0 & 6.7 & 23.1 & 0.49 \\
Green chop & 11.4 & 6.7 & 7.7 & $>0.99$ \\
Fat/tallow & $0^{\mathrm{b}}$ & $60.0^{\mathrm{a}}$ & $76.9^{\mathrm{a}}$ & $<0.01$ \\
Blood meal & $0^{\mathrm{b}}$ & $46.7^{\mathrm{a}}$ & $46.2^{\mathrm{a}}$ & $<0.01$ \\
Whole cottonseed & $0^{\mathrm{b}}$ & $40.0^{\mathrm{a}}$ & $53.9^{\mathrm{a}}$ & $<0.01$ \\
Brewery byproducts & $0^{\mathrm{b}}$ & $40.0^{\mathrm{a}}$ & $23.1^{\mathrm{a}}$ & $<0.01$ \\
Bakery byproducts & 0 & 6.7 & 0 & 0.42 \\
Feather/poultry meal & 0 & 6.7 & 0 & 0.44 \\
Porcine meat/bone meal & $0^{\mathrm{b}}$ & $4.0^{\mathrm{b}}$ & $38.5^{\mathrm{a}}$ & $<0.01$ \\
\hline
\end{tabular}

$\overline{\mathrm{a}, \mathrm{b}}$ Different superscripts in the same row indicate statistically different frequencies.

${ }^{1}$ Certified organic (ORG) and small conventional (SC) herds had $<200$ mature cows (i.e., dry and milking); medium conventional (MC) herds had $\geq 200$ mature cows.

very commonly supplemented rations with kelp (82.9\%), which was not done at all by conventional herds $(P<$ 0.01, Table 5). Furthermore, herds in all 3 groups commonly reported the supplementation of vitamins $\mathrm{A}, \mathrm{D}$, and $\mathrm{E}$ in feed, but the injection of vitamins was more frequently practiced on ORG and $\mathrm{SC}$ herds than on MC herds (Table 6). Most herds (>50.0\%) also added vitamins $\mathrm{A}, \mathrm{D}$, and $\mathrm{E}$ to the ration of calves $(P=0.78)$. Ionophores were not added by any of the ORG producers, but they were added to the ration of cows and heifers on 40.0 and $66.7 \%$ of SC and 92.3 and $50.0 \%$ of $\mathrm{MC}$ herds, respectively. Conversely, one-quarter to onethird of herds (ORG: $27.3 \%$, SC: $33.3 \%$, MC: $23.1 \%, P$ $=0.86)$ fed probiotics in cows or calves $(P>0.99)$, yet only ORG herds also used probiotics in heifers (19.4\%).
Interestingly, ORG producers were less likely to limit potassium in the dry cow ration as a means of preventing milk fever compared with conventional herds.

\section{Manure Management}

Some ORG farms $(\mathrm{n}=4)$ and $\mathrm{SC}$ farms $(\mathrm{n}=2)$ did not have manure storage and thus hauled manure away daily. Otherwise, lagoons or pits, with or without piles for solids, were the most commonly encountered manure storage type. The manure was commonly spread over future forage or feed (ORG: $57.1 \%$, SC: $20.0 \%$, MC: $46.2 \%, P=0.06$ ), crops (ORG: $62.9 \%$, SC: $93.3 \%$, MC: $92.3 \%, P=0.03$ ), or over pastures after animals had been grazing on them (ORG: $34.3 \%$, SC: $6.7 \%$,

Table 6. Frequency of routine administration of medications and supplements, reported as percent of herd type

\begin{tabular}{lcccc}
\hline & \multicolumn{3}{c}{ Herd type $^{1}$} & \\
\cline { 2 - 3 } Feed supplement & ORG & SC & MC & P-value \\
\hline Vitamin A-D-E (in feed) & $74.3^{\mathrm{b}}$ & $100^{\mathrm{a}}$ & $100^{\mathrm{a}}$ & 0.02 \\
Selenium (in feed) & 65.7 & 78.6 & 91.7 & 0.21 \\
Vitamin A-D-E (injectable) & 34.3 & 33.3 & 7.7 & 0.15 \\
Probiotics & 28.6 & 60.0 & 41.7 & 0.10 \\
Limited potassium (in dry cow feed) & $22.9^{\mathrm{b}}$ & $53.3^{\mathrm{a}}$ & $83.3^{\mathrm{a}}$ & $<0.01$ \\
Selenium (injectable) & 17.1 & 13.3 & 0 & 0.35 \\
Coccidiostats in feed & $2.9^{\mathrm{b}}$ & $57.1^{\mathrm{a}}$ & $58.3^{\mathrm{a}}$ & $<0.01$ \\
Ionophores in feed (e.g., monensin) & $0^{\mathrm{b}}$ & $80.0^{\mathrm{a}}$ & $100^{\mathrm{a}}$ & $<0.01$ \\
Other & 11.4 & 20.0 & 38.5 & 0.10 \\
\hline
\end{tabular}

$\overline{\mathrm{a}, \mathrm{b}}$ Different superscripts in the same row indicate statistically different frequencies.

${ }^{1}$ Certified organic (ORG) and small conventional (SC) herds had $<200$ mature cows (i.e., dry and milking); medium conventional (MC) herds had $\geq 200$ mature cows. 
MC: $0 \%, P=0.01)$. However, although none of the herds applied manure on pastures while animals were still grazing, some ORG herds $(17.1 \%)$ applied manure on pastures before animals would graze them (SC and MC: $0 \%, P=0.10)$. Furthermore, both ORG (37.1\%) and SC herds $(46.7 \%)$ were less likely than MC herds $(100 \%)$ to measure the manure nitrogen, phosphorus, or potassium before applying it to the environment $(P$ $<0.01)$.

\section{DISCUSSION}

This study provides new information regarding common management practices of organic and small and medium-sized conventional dairy farms in Minnesota. Organic herds were, on average, smaller than the average herd in Minnesota, which was milking 105 cows in 2010 (Progressive Dairyman, 2013). However, participating ORG farms and farmers were, on average, in business just as long as the other participating farms. Surprisingly, the most common reason for farming organically was not an economic decision, but was primarily driven by the concerns about the use of chemicals during fieldwork and its perceived negative effect on health instead; some producers reported the effect of chemicals on their own health. The risk of pesticide poisoning in agricultural fieldwork has been well established (Osorio, 2007), although the effect of chronic low doses on human health (e.g., neurotoxicity) needs to be investigated further (Keifer and Firestone, 2007).

Although the herds had been established at similar times, the herds' breed composition was different between herd types. Unlike conventional herds, the ORG herds were predominantly crossbred and older cows (i.e., third and higher lactation), which was consistent with an earlier study (Stiglbauer et al., 2013). Crossbred cows are preferred by ORG producers because of their perceived greater survival and fertility rates compared with purebred Holstein cows (Buckley et al., 2014). Yet, although the average cow was indeed older in ORG herds, the age of the oldest cow did not differ between farms regardless of farming type or breed composition. Whether the older age distribution of the ORG herds is due to hardier crossbred cows or driven by culling decisions cannot be answered with these data. Because the ORG herds of this study were less likely to cull for poor production than conventional herds (our unpublished data) and Smith et al. (2000) reported that herds with low production were less likely to cull cows, one might speculate that cows' age is likely driven by culling decisions rather than improved longevity in this study. The ORG herds did not dock tails and were more likely to use breeding bulls and less likely to use routine pregnancy exams than conventional herds. Although the absence of tail docking on ORG farms is consistent with NOP guidelines (AMS, 2015), use of bulls and lack of pregnancy exams have to be considered the preference of producers. Artificial insemination is allowed under the NOP (AMS, 2015), but because ORG producers often state that they rarely need to consult a veterinarian for sick cow work, this may then lead to fewer veterinary visits for reproductive programs and the use of bulls as "clean-up bulls" as no hormonal therapy for reproductive failure could be used under the NOP (AMS, 2015). The lower use of veterinary advice may also be reflected in less frequent use of dystocia scoring systems in ORG herds compared with the conventional herds. An unexpected observation was that more heifers and cows of SC herds experienced dystocia than those on ORG and $\mathrm{MC}$ herds. Considering that both $\mathrm{SC}$ and $\mathrm{MC}$ herds were predominantly Holstein cattle, this observation is probably not due to breed predisposition (Olson et al., 2009) but rather driven by management practices that cannot be distinguished based on the present herd-level data.

Small conventional herds were less likely to have a parlor or to use gloves during milking compared with similar sized ORG herds or larger MC herds and tended to be less likely to forestrip their cows. The reason for either is not known. One might speculate that the former is because the herd owner is the predominant milker in SC herds, and (s)he may be uncomfortable wearing gloves or does not see the need for them. Although glove use was associated with a lower laboratory pasteurization count (LPC) on farm (Sorge, 2014), it was not associated with the bulk tank SCC on farms in this study, and might be indicative of poor premilking teat cleaning (Bade et al., 2008). Furthermore, in agreement with NAHMS (USDA-NAHMS, 2009), some ORG and SC herds did not use pre- or postdip on their cows even though their benefit for mastitis prevention has been shown (Morton et al., 2014).

The primary housing type of animals shifted between seasons in these Minnesota herds. The predominant housing type for preweaned heifers was individual hutches or pens. This is similar to the USDA-NAHMS (2007) study. However, weaned heifers were more likely to be housed outdoors or in 3-sided sheds, and more herds used freestalls and fewer herds used tiestalls compared with the national average (USDA-NAHMS, 2007). Although different housing types were used for the mature cow herds of different types of herds, MC herds did not use tiestalls at all, which is comparable to observations by Brotzman et al. (2015). Furthermore, ORG provided more access to pasture for mature cows than did conventional farms. This will likely have resulted in the lower risk of hock lesions on ORG cows 
of this study (our unpublished data) and the study by Rutherford et al. (2008), because Kester et al. (2014) found that increased pasture access was associated with fewer hock lesions on dairy farms. Interestingly, 2 ORG farms reported housing their milking herd outside during the winter. Considering that the average temperature during the winter ranges from $-4^{\circ} \mathrm{C}$ to $-16^{\circ} \mathrm{C}$ in different regions of Minnesota (Minnesota DNR, 2003), frostbite on teats after milking is probable. It was interesting to note that, although organic regulations specifically emphasize the importance of sanitation practices for disease prevention (AMS, 2015), the hygiene of the farm environment and cows did not differ between farm types.

The investigation of conventional herds with or without pasture access as well as pasture-based organic herds highlighted several things. First, the participating conventional herds were not intensive-grazing herds. Pasture was not considered an important nutritional source for their cows, conventional producers rarely used rotational grazing to optimize the usage of available pasture, conventional herds also had considerably less pasture, and only $1 \mathrm{SC}$ producer analyzed the pasture for its nutritional value or considered the amount of grass consumed by cows in their feeding program. Interestingly, very few ORG herds used analysis of pasture clippings to estimate the nutritional value or pasture yield either. Instead, most used an algorithm similar to that suggested by the USDA (AMS, 2012). Briefly, to calculate the DMI from pasture, the DMI from supplemented feed during the grazing season is deducted from the total DMI of a cow based on the BW of cattle. One ORG farmer unexpectedly denied assessing the nutritional value or the amount of grass consumed through pasture by their herd. This is surprising as ORG certification requires the farmer to demonstrate that at least $30 \%$ of the DMI during a grazing season of at least $120 \mathrm{~d}$ is derived from pasture. Because the farmer was certified, one might speculate that (s)he might have misunderstood the questions. Nevertheless, one would have expected a more thorough analysis of the pasture, given the NOP requirement. Although we did not record body condition scores, the low intensity of pasture assessments may contribute to the observation by Bergman et al. (2014) that ORG and conventional grazing herds were less likely to have many cows with a BCS $>4$ on a 5 -point scale.

Second, the forages and supplements fed were diverse across farm types. Although all conventional farmers used corn, corn silage, and alfalfa hay/haylage as their base for rations for the lactating herds and commonly added ionophores to rations, ORG farmers did not do so. However, the latter is not surprising, as the NOP prohibits the routine use of parasiticides or antibiotics and does not allow use of ionophores. In contrast, a popular feed additive on most ORG farms was kelp, which was not fed on any conventional farms. Kelp or brown seaweed, most commonly Ascophyllum nodosum, is an iodine-rich mineral supplement. Mostly anecdotal reports claim its benefit to animal health, including prevention of keratoconjunctivitis ("pink eye") and reduction in incidence of lameness. However, studies to substantiate these reports are currently lacking. Future studies are needed to evaluate the effects of kelp on animal health and milk composition.

In summary, although we observed differences across farm types regarding breeds and age distributions, uses of pasture, forages, and feed additives, reproductive management, and tail docking, observations in other management areas showed large similarities across herd types. The present results indicate that management choices are diverse and farm specific and are not solely dependent on the organic or nonorganic status of herds.

\section{ACKNOWLEDGMENTS}

The authors thank the USDA National Institute of Food and Agriculture (Washington, DC) for the financial support of this study and the dairy farmers for participating.

\section{REFERENCES}

AMS (Agricultural Marketing Service). 2012. NOP pasture assessment. Accessed January 2015. www.ams.usda.gov/AMSv1.0/ nopaccesstopasture.

AMS (Agricultural Marketing Service). 2015. National Organic Program Regulations. http://www.ecfr.gov/cgi-bin/textidx?c = ecfr\&sid = 3f34f4c22f9aa8e6d9864cc2683cea02\&tpl = / ecfrbrowse/Title07/7cfr205_main_02.tpl.

Bade, R. D., D. J. Reinemann, and P. D. Thompson. 2008. Method for Assessing Teat and Udder Hygiene. Paper 083796 in Proc. 2008 ASABE Annual International Meeting, Providence, Rhode Island. ASABE, St. Joseph, MI.

Bergman, M. A., R. M. Richert, K. M. Ciccioni-Hogan, M. J. Gamroth, Y. H. Schukken, K. E. Stiglbauer, and P. L. Ruegg. 2014 Comparison of selected animal observations and management practices used to assess welfare of calves and adult dairy cows on organic and conventional dairy farms. J. Dairy Sci. 97:4269-4280.

Brotzman, R. L., D. Döpfer, M. R. Foy, J. P. Hess, K. V. Nordlund, T. B. Bennett, and N. B. Cook. 2015. Survey of facility and management characteristics of large, Upper Midwest dairy herds clustered by Dairy Herd Improvement records. J. Dairy Sci. 98:8245-8261.

Buckley, F., N. Lopez-Villalobos, and B. Heins. 2014. Crossbreeding: Implications for dairy cow fertility and survival. Animal 8(Suppl. 1):122-133.

Cabaret, J. 2003. Animal health problems in organic farming: Subjective and objective assessments and farmers' actions. Livest. Prod. Sci. 80:99-108.

COS. 2011. National Standard of Canada: Organic Production Systems: General Principles and Management Standards. CAN/ CGSB-32.310-2006. Canadian General Standards Board, Gatineau, QC, Canada.

ERS (Economic Research Service). 2014. Organic market overview. Accessed Nov. 17, 2015. http://www.ers.usda.gov/topics/natural- 
resources-environment/organic-agriculture/organic-marketoverview.aspx.

European Union. 2007. Council Regulation (EC) No 834/2007 of 28 June 2007 on organic production and labelling of organic products and repealing Regulation (EEC) No 2092/91. Accessed January 2015. http://www.wipo.int/wipolex/en/details.jsp?id $=7876$.

Fall, N., Y. T. Gröhn, K. Forslund, B. Essen-Gustafsson, R. Niskanen, and U. Emanuelson. 2008. An observational study on early-lactation metabolic profiles in Swedish organically and conventionally managed dairy cows. J. Dairy Sci. 91:3983-3992.

Garmo, R. T., S. Waage, S. Sviland, B. I. Henriksen, O. Østerås, and O. Reksen. 2010. Reproductive performance, udder health, and antibiotic resistance in mastitis bacteria isolated from Norwegian Red cows in conventional and organic farming. Acta Vet. Scand. $52: 11-13$.

Haskell, M. J., F. M. Langford, M. C. Jack, L. Sherwood, A. B. Lawrence, and K. M. D. Rutherford. 2009. The effect of organic status and management practices on somatic cell counts on UK dairy farms. J. Dairy Sci. 92:3775-3780.

Ivemeyer, S., M. Walkenhorst, F. Heil, C. Notz, A. Maeschli, G. Butler, and P. Klocke. 2009. Management factors affecting udder health and effects of a one-year extension program in organic dairy herds. Animal 3:1596-1604.

Keifer, M. C., and J. Firestone. 2007. Neurotoxicity of pesticides. J. Agromedicine 12:17-25.

Kester, E., M. Holzhauer, and K. Frankena. 2014. A descriptive review of the prevalence and risk factors of hock lesions in dairy cows. Vet. J. 202:222-228.

McBride, W. D., and C. Greene. 2007. A comparison of conventional and organic milk production systems in the U. S. Presented at Am. Agric. Econ. Assoc. Mtg. Accessed Jan. 5, 2015. http://purl. umn.edu/9680.

Minnesota DNR. 2003. Normal mean temperature December-February Accessed January 2015. http://climate.umn.edu/img/normals/ mean_temp_norm_adj/mean_temp_norm_adj_12-02.htm.

Morton, J. M., J. F. Penry, J. Malmo, and G. A. Mein. 2014. Premilking teat disinfection: Is it worthwhile in pasture-grazed dairy herds? J. Dairy Sci. 97:7525-7537.

Olson, K. M., B. G. Cassell, A. J. McAllister, and S. P. Washburn. 2009. Dystocia, stillbirth, gestation length, and birth weight in
Holstein, Jersey, and reciprocal crosses from a planned experiment. J. Dairy Sci. 92:6167-6175.

Osorio, A. M. 2007. Surveillance for pesticide-related disease. J. Agromedicine 12:57-66.

Progressive Dairyman. 2013. 2012 US Dairy Statistics. Accessed July 7, 2015. http://www.progressivedairy.com/home/about-us/2012us-dairy-stats.

Richert, R. M., K. M. Cicconi, M. J. Gamroth, Y. H. Schukken, K. E. Stiglbauer, and P. L. Ruegg. 2013. Risk factors for clinical mastitis, ketosis, and pneumonia in dairy cattle on organic and small conventional farms in the United States. J. Dairy Sci. 96:4269-4285.

Rotz, C. A., G. H. Kamphuis, H. D. Karsten, and R. D. Weaver. 2007 Organic dairy production systems in Pennsylvania: A case study evaluation. J. Dairy Sci. 90:3961-3979.

Rutherford, K. M. D., F. M. Langford, M. C. Jack, L. Sherwood, A. B. Lawrence, and M. J. Haskell. 2008. Hock injury prevalence and associated risk factors on organic and nonorganic dairy farms in the United Kingdom. J. Dairy Sci. 91:2265-2274.

Smith, J. W., L. O. Ely, and A. M. Chapa. 2000. Effect of region herd size and milk production on reasons cows leave the herd. J. Dairy Sci. 83:2980-2987.

Sorge, U. S. 2014. Health and disease on organic dairy farms in Minnesota. Minnesota Dairy Health Conference, Minneapolis, MN. University of Minnesota, Saint Paul.

Stiglbauer, K. E., K. M. Cicconi-Hogan, R. Richert, Y. H. Schukken, P. L. Ruegg, and M. Gamroth. 2013. Assessment of herd management on organic and conventional dairy farms in the United States. J. Dairy Sci. 96:1290-1300.

Sundberg, T., B. Berglund, L. Rydhmer, and E. Strandberg. 2009. Fertility, somatic cell count and milk production in Swedish organic and conventional dairy herds. Livest. Sci. 126:176-182.

USDA-NAHMS. 2007. Dairy 2007, Part I: Reference of Dairy Cattle Health and Management Practices in the United States, 2007. \#N480.1007. USDA-APHIS-VS, CEAH, Fort Collins, CO.

USDA-NAHMS. 2009. Dairy 2007, Part V: Changes in Dairy Cattle Health and Management Practices in the United States, 19962007. \#519.0709. USDA-APHIS-VS, CEAH, Fort Collins, CO.

Vaarst, M., S. Padel, M. Hovi, D. Younie, and A. Sundrum. 2005. Sustaining animal health and food safety in European organic livestock farming. Livest. Prod. Sci. 94:61-69. 